\title{
Applying Transdisciplinary Engineering (TE) Design Research Methodology to the Challenge of Managing Decision Support Tool Performance
}

\author{
Susan LATTANZIO ${ }^{\mathrm{a}, 1}$, Linda B. NEWNES ${ }^{\mathrm{a}}$, Marcelle MCMANUS a ${ }^{\text {, Alex HULTIN }}{ }^{\mathrm{a}}$ \\ and Derrick DUNKLEY ${ }^{\mathrm{b}}$ \\ ${ }^{\mathrm{a}}$ The University of Bath, Bath, UK \\ ${ }^{\mathrm{b}}$ National Grid, Warwick, UK
}

\begin{abstract}
Over the past few decades there has been increasing dialogue around transdisciplinary (TD) research. However, within engineering it has received less attention and there remains a lack of consensus over both the definition, and the methods through which to conduct transdisciplinary engineering (TE). Within this paper we describe and outline the salient points of TD and the Design Research Methodology (DRM) and create a proposal to combine the two. A case study of National Grid Electric Transmissions (NGET) demonstrates application. The case study shows that through TE DRM a conceptual process for managing decision support tool (DST) performance is created. This process integrates academic and non-academic perspectives. Evaluation, by NGET subject matter experts found the process to be logical and useable within NGET, with approval given to proceed to implementation. Conclusions find that application of TE DRM increases the possibility of industry uptake and the potential impact of academic research.
\end{abstract}

Keywords. Design Research Methodology, Transdisciplinary Engineering, Transdisciplinarity, Transdisciplinary Research

\section{Introduction}

In the current funding environment there is a growing pressure to undertake research which has societal benefit [1][2][3]. Transdisciplinary (TD) approaches advocate purposive research conducted in the service of society [4]. Over recent years there has been an exponential growth in the number of academic papers which specifically reference the term TD (Figure 1).

Despite the increased academic interest, there remains a plurality of definitions [5][6], and no collectively accepted methodology for undertaking TD research within the engineering discipline. This paper contributes to the discourse in the area of TE design research methodology by defining key characteristics to be incorporated when undertaking TD research within engineering and demonstrating application within a case study research project.

\footnotetext{
${ }^{1}$ Corresponding Author, Email: S.Lattanzio@bath.ac.uk.
} 


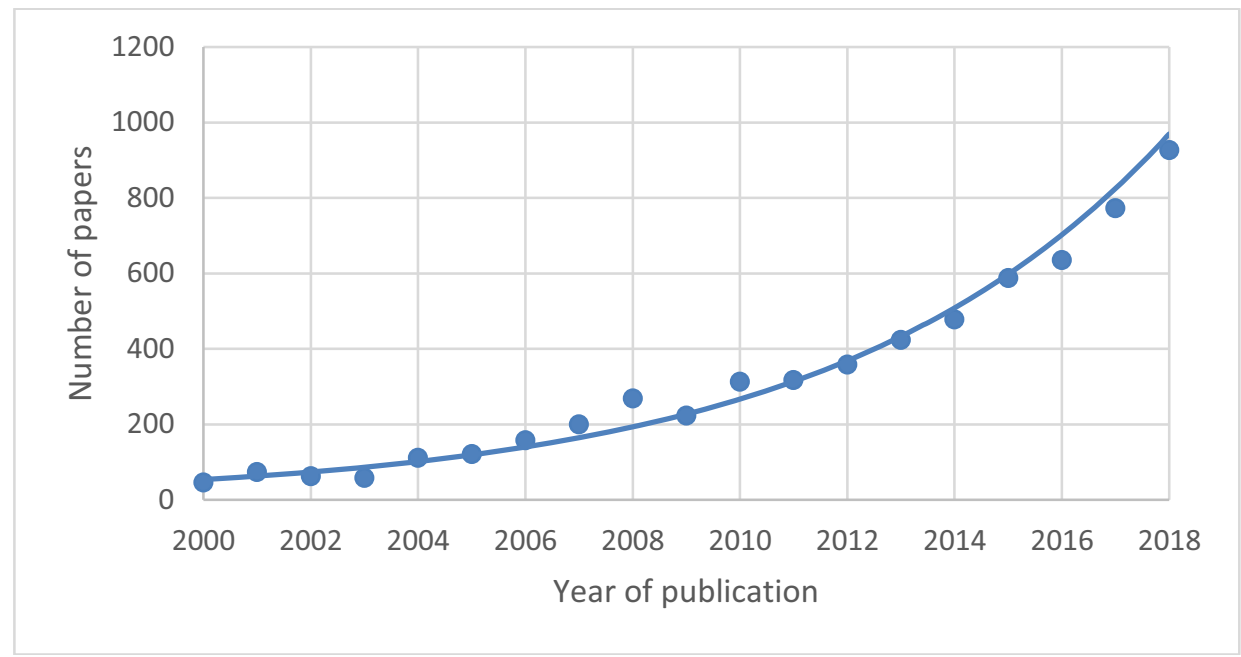

Figure 1. Number of papers with "Transdisciplinary" in the title, abstract, or keywords by year as per the Scopus database.

The paper is structured as follows. First, a brief background to TD (1). Within this section the work of Jantsch [7] is proposed as an approach through which to conceptualise TE. Next, the four stages seen with the Design Research Methodology (DRM), are are considered in conjunction with the hierarchical education/innovation system proposed by Jantsch [7] as a means of defining key characteristics to be incorporated in TE design research (2). A research project conducted in collaboration within National Grid Electricity Transmissions - the owner / operator of the UK electricity transmission network - is presented as an exemplar of the application of TE design research methodology (3). Conclusions are formulated (4) and future work identified (5).

\section{Transdisciplinarity}

There remains a plurality of definitions of TD. There is general agreement that there is a hierarchy of disciplinarity which starts with mono- and ends with transdisciplinarity, and moving from one level to the other is dependent on overcoming the various disciplinarity boundaries. Where definitions fail to agree is the inherent characteristics which would make something TD, rather than one of the other levels of disciplinarity [5]. In an attempt to introduce order a number of frameworks through which to categorise disciplinarity have been developed [1][8][7][9][10][11][12][13][14][15][16]. Despite these academic efforts variability in ontological and epistemological positions persist.

Given this inconsistency when communicating about transdisciplinary engineering (TE), it is essential to identify the concept of TD which underpins the work [11]. Within this paper, the adopted definition of TD is established in Jantsch [7]. Although, alternative approaches were considered Jantsch's work was the earliest enunciation of TD and as such foundational in the field.

In his work Jantsch used a systems approach to define a hierarchical system of education / innovation (Figure 2). 


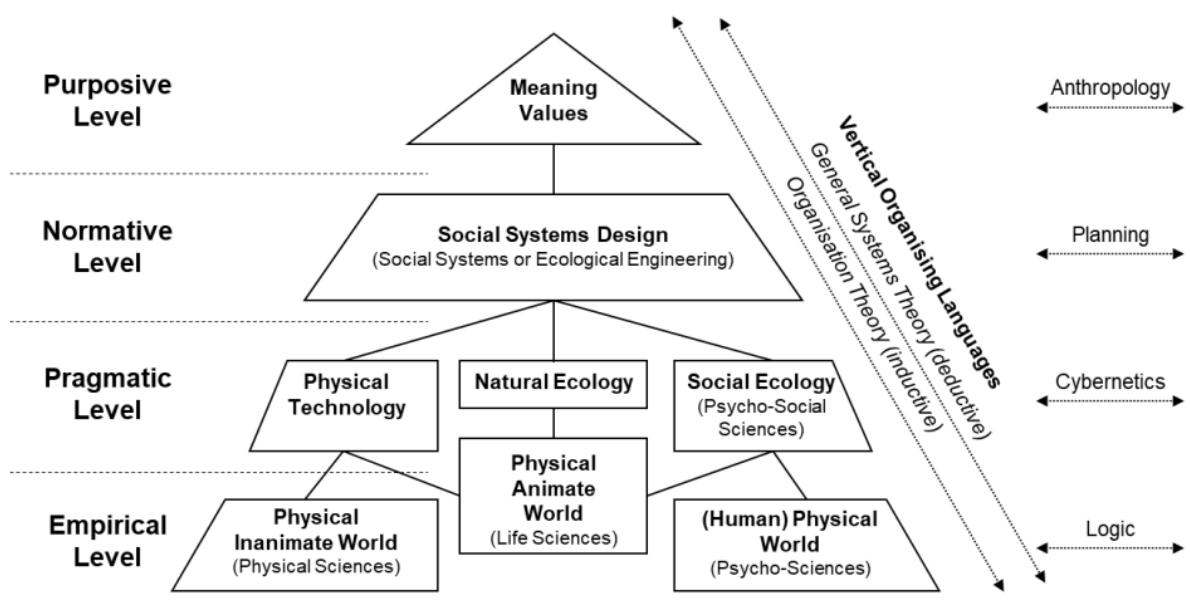

Figure 2. The education/innovation system, viewed as a multi-level multi-goal, hierarchical system [7].

The hierarchy is presented as a pyramid. The purposive level defines the societal meaning and value. To achieve this societal benefit requires engagement at the normative, pragmatic, and empirical levels. The empirical level are the 'pure' scientific disciplines such as mathematics, physics, and psychology. The pragmatic level comprises of the applied sciences, at this point theories found in the 'pure' disciplines are merged and trimmed. Engineering is within this pragmatic level. The normative level is the systems that society has put in place to realise its goals i.e. policies, regulations, standards.

Applying this hierarchy Jantsch defined five levels of disciplinarity: multi-, pluri-, cross-, inter-, and transdisciplinarity (Figure 3).

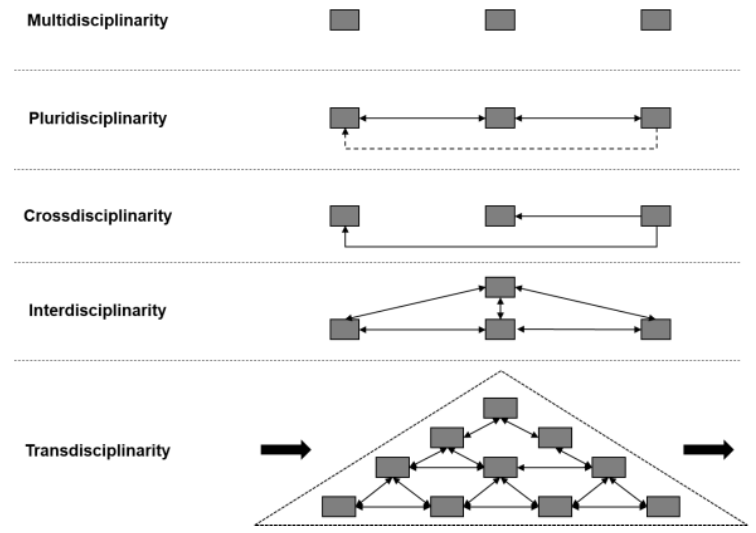

Figure 3. Steps of disciplinarity system configuration [7].

Multi-, pluri, and crossdisciplinarity occur at one level of the pyramid. Although there may be some interaction, they are not coordinated towards a common goal. Interdisciplinarity brings together two adjacent levels, with coordination from the higher level. Only in TD are all four levels of the pyramid engaged. It is coordination on the basis of a generalized axiomatics, introduced from the purposive level down. 


\section{Transdisciplinary Engineering (TE) Design Research Methodology}

This papers contributes to the discourse on TE design research methodology by creating a a proposal which combines the conceptualisation of Jantsch with the Design Research Methodology (DRM). Within this section the generic DRM is briefly described (2.1). Following, the four stages of the DRM are considered in conjunction with the work of Jantsch as a means to define key characteristics of a TE research design methodology (2.2).

\subsection{Design Research Methodology (DRM)}

DRM provides a framework for undertaking design research projects and programmes [17]. Commonly used in engineering, it aims to improve the efficiency and effectiveness of design research (Figure 4).

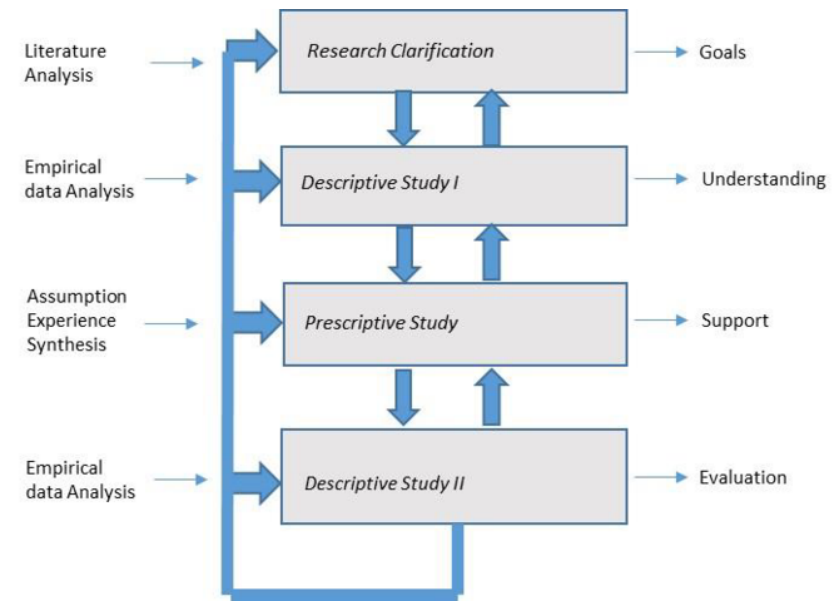

Figure 4. DRM Research Framework [17].

The methodology has four stages. Research Clarification evidences that a realistic and worthwhile research goal exists. Within the Descriptive Study I stage additional information that improves the clarity of the research challenge and informs how it might be addressed is gathered. The Prescriptive Study I stage is the point at which understanding gained during the previous two stages is applied in the creation of a 'support' (novel procedure, tool, or technique etc.) During the Descriptive Study II stage the impact of the 'support' and its ability to realise the desired situation is evaluated.

\subsection{DRM and Transdisciplinary Engineering Research}

Although the DRM provides a methodology which can be applied when conducting TD research, following the prescribed stages of the DRM does not in itself evidence that TE design research has been performed. By considering the stages of the DRM in conjunction with the conceptualisation of TD provided in the Jantsch [7], key characteristics to be incorporated within a TE design research methodology are defined.

Research clarification is concerned with setting the goals for the research project. These goals can be either to increase scientific understanding, to address a real-world 
challenge, or a mixture of both [8]. Jantsch recognises that although each has value [7], within TD research and innovation consideration of societal meaning and value should be explicit, with research coordinated from this purposive level down.

Descriptive Study I is the point at which understanding is gained which will inform the design of the support. Within Jantsch's hierarchy the normative level enforces consideration of the social system context in which the support will operate. Consequently, within a TE design research methodology there should be engagement with non-academic perspectives.

Prescriptive Level I is where the support (tool, method or approach), is created. The design of the support is informed by goals and understanding generated during the previous two stages. That is, the design of the support should integrate both academic and non-academic data.

Descriptive Study II. The goal of TE design research is to create a support which offers societal meaning and value. To evaluate whether that has been achieved evaluation should be undertaken by those capable of assessing the extent to which it meets that goal.

The following case study demonstrates application of of TE DRM within an engineering research project.

\section{Case Study: National Grid Electricity Transmissions (NGET)}

Economic growth and human well-being are intrinsically linked to having the right energy, water, transport and communication infrastructure. To achieve adequate infrastructure levels estimates are that global annual investment will increase from US\$4 trillion per year in 2012, to more than US\$9 trillion per year by 2025 [18]. The real-world challenge is raising the money to fund this expenditure. Research undertaken in collaboration with NGET, the owner /operator of the UK electric transmission network, aimed to address this challenge.

\subsection{DST Performance Management Process}

One approach for mitigating the amount of money required for infrastructure is to improve investment productivity. Estimates suggest that by addressing productivity in the areas of selecting, building, operating, and managing infrastructure there is the possibility of saving US\$1 billion per annum [19]. The output of the research was a process for managing the performance of decision support tools (DSTs). DSTs are the manual processes and computer based tools used by infrastructure organisations to support decisions about what assets to acquire and how to manage them.

The DST Performance Management Process (Figure 5) represents a risk-based approach in which the DSTs are managed in the same way as infrastructure organisations manage their physical engineered assets. 


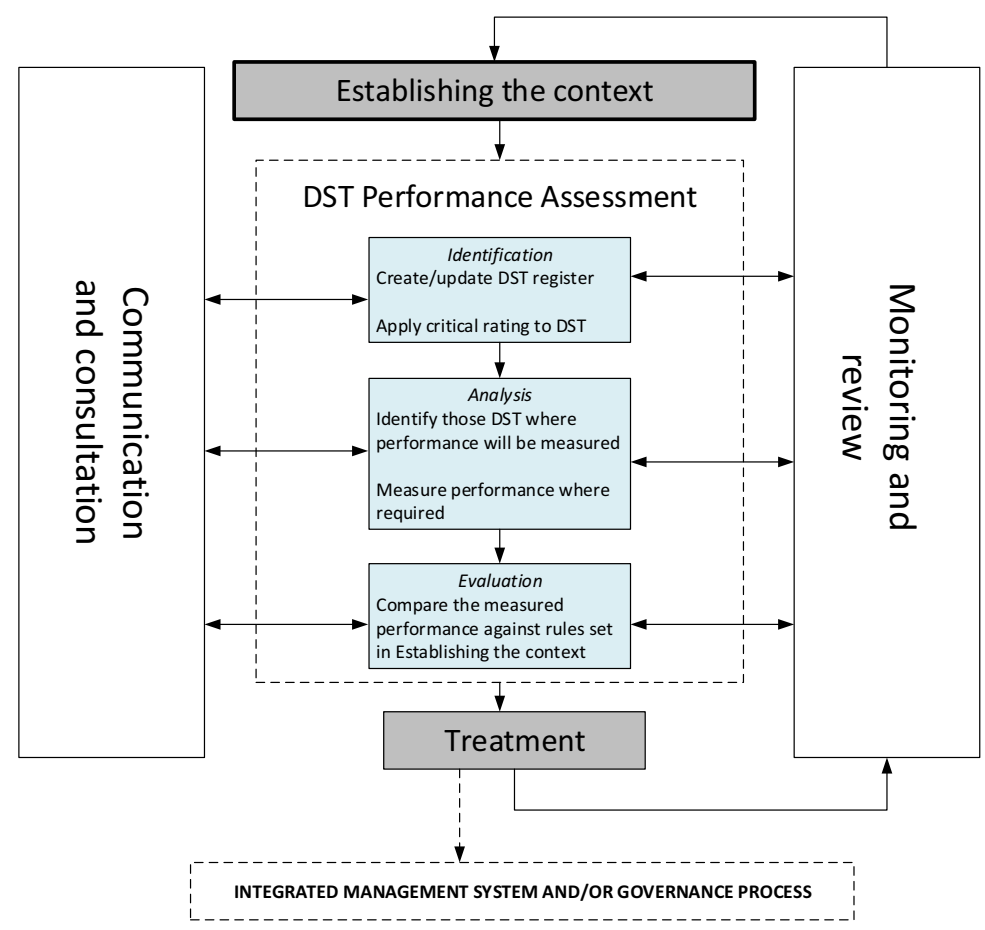

Figure 5. DST Performance Management Process.

\subsection{Methodology}

Within section 2 the key characteristics of a TE DRM were identified. Table 1 details the research activities undertaken within the case study of NGET.

Table 1. Mapping of DRM stage to TE characteristic and activity undertaken.

\begin{tabular}{ll}
\hline DRM Stage & TE Activity \\
\hline Research Clarification & Top down approach: \\
(Goal) & Practitioner survey \\
\hline Descriptive Study I & Generation of understanding from non-academic sources: \\
(Understanding) & Industry case study \\
& Stakeholder Requirements Engineering exercise \\
\hline Prescriptive Study & Integration of academic and non-academic understanding: \\
(Support) & Support design informed by data derived from both academic sources and \\
& engagement with stakeholders \\
\hline Descriptive Study II & Evaluation by those capable of assessing the extent to which it meets its \\
(Evaluation) & goal: \\
& Evaluation by NGET subject matter experts \\
\hline
\end{tabular}

Research Clarification: The driver of this project was to deliver societal meaning and value. The academic literature review identified that DSTs were being created but little consideration was given to their performance once operational. Although, a 
research gap this did not necessarily mean that an industry challenge existed. If the performance of DSTs did not change (or if the performance change was always in a positive direction), there may be no need for approaches to manage DST performance. To ensure that there was a societal benefit to be gained an empirical study was conducted amongst practitioners working in the field. Analysis of the qualitative inputs of subject matter experts, working in sixteen key UK and international infrastructure organisations and asset consultancies, found support for the occurrence of performance decay $(\sim 81 \%)$.

Descriptive Study I: During this stage understanding which informs the design of the support is elicited. TE design research must recognise the social context in which the support will operate. In this exemplar empirical data was generated by way of a case study of National Grid Electric Transmissions (NGET) and through a stakeholder Requirements Engineering exercise. Key findings were: (1) control and governance of DST performance was undertaken within NGET but efforts were uncoordinated and ad-hoc, rather than by way of a systematic process. (2) within an asset management context any approach for managing DST performance should align to the international standard for asset management, ISO 5500x:2014.

Prescriptive Study I: Understanding gained from the previous stages was used to inform the design of the DST Performance Management Process. The result was a process for managing DST performance, which aligned with the international standard for Asset Management. Incorporated within this process the means through which to measure performance was based on the academic work of Delone and McClean [20][21]. Thus, academic theory is embedded within a framework designed to meet the needs and requirements of the stakeholders.

Descriptive Study II: The evaluation of the support was based on whether NGET subject matter experts considered it to be both logical and useable. Throughout this research, activities were taken to elicit and integrate stakeholder perspectives. Therefore, it was expected that their evaluation would be positive. Accordingly, the results of the evaluation found the process to be logical and useable, with agreement secured to proceed to implementation within NGET.

\section{Conclusion}

A case study of NGET demonstrates application of TE DRM. Throughout this research activities were undertaken to elicit and integrate stakeholder perspectives within the solution. Accordingly, evaluation showed the support to be both logical and useable within industry, and resulted in the securing of approval to progress to implement within NGET. The conclusion of this work is that TE DRM increases the chances that a support will be considered logical and useable outside of academia. In turn, this increases the possibility of uptake, and ultimately the potential impact of academic research.

\section{Future Work}

There exists a plurality of definitions of TD within academia. Achieving consensus across all disciplines if not impossible, would require considerable effort and may prove to be undesirable. However, to communicate and strengthen local projects and 
achieve common goals requires a mutual understanding. Future work should focus on achieving a consensus of how TD should be conceptualised within the engineering field. Once achieved, efforts can focus on the development of the theoretical foundations required to underpin TE methodologies.

\section{Acknowledgement}

This research was supported by the Engineering and Physical Sciences Research Council (EPSRC) and National Grid (EP/R013179).

\section{References}

[1] G. Carr, D.P. Loucks and G. Blöschl, Gaining insight into interdisciplinary research and education programmes: A framework for evaluation. Research Policy, 2018, Vol. 47, pp. 35-48.

[2] M. Gulbrandsen, D. Mowery and M. Feldmann, Introduction to the special section: heterogeneity and university-industry relations. Research Policy, 2011, Vol. 40, pp. 1-5.

[3] D.C. Mowery, R.R. Nelson, B.N. Sampat and A.A. Ziedonis, The growth of patenting and licensing by US universities: an assessment of the effects of the Bayh-Dole act of 1980. Research Policy, 2001, Vol. 30, 99-119.

[4] Centre For Educational Research Innovation, 1972. Interdisciplinarity : Problems of teaching and research in Universities, Belgium, OECD Publications.

[5] C. Pohl and G.H. Hadorn, Principles for Designing Transdisciplinary Research, Swiss Academies of Arts and Sciences, 2007.

[6] N.N., td-net Networkd for Trandiscplinary Research, Swiss Acadamies of Arts and Sciences, 2018, http://www.transdisciplinarity.ch/en/td-net/Ueber-td-net.html, accessed Oct 4, 2018.

[7] E. Jantsch, Inter- and Transdisciplinary University: A Systems Approach to Education and Innovation. Policy Sciences, 1970, Vol. 1, No. 1, pp. 403-428.

[8] K. Huutoniemi, J.T. Klein, H. Bruun and J. Hukkinen, Analyzing interdisciplinarity: Typology and indicators. Research Policy, 2010, Vol. 39, pp. 79-88.

[9] B. König, K. Diehl, K. Tscherning and K. Helming, A framework for structuring interdisciplinary research management. Research Policy, 2013, Vol. 42, pp. 261-272.

[10] L.R. Lengwiler, Between charisma and heuristics: four styles of Interdisciplinarity. Science and Public Policy, 2001, Vol. 33, pp. 423-434.

[11] C. Mitchell, D. Cordell and D. Fam, Beginning at the end: The outcome spaces framework to guide purposive transdisciplinary research. Futures, 2015, Vol. 65, pp. 86-96.

[12] C. Pohl, L. Van Kerkhoff, G. Hirsch Hadorn and G. Bammer, Integration,. In: G. Hirsch Hadorn, et al (eds.) Handbook of Transdisciplinary Research, Springer, Netherlands, 2008, pp. 411-424.

[13] F.A. Rossini and A.L. Porter, Frameworks for integrating interdisciplinary research. Research Policy, 1979, Vol. 8, pp. 70-79.

[14] M. Stember, Advancing the Social Sciences Through the Interdisciplinary Enterprise, The Social Science Journal, 1991, Vol. 28, pp. 1-14.

[15] F.J. Van Rijnsoever and L.K. Hessels, Factors associated with disciplinary and interdisciplinary research collaboration. Research Policy, 2011, Vol. 40, pp. 463-472.

[16] C.S. Wagner, J.D. Roessner, K. Bobb, J.T. Klein, K.W. Boyack, J. Keyton, I. Rafols and K. Börner, Approaches to understanding and measuring interdisciplinary scientific research (IDR): A review of the literature. Journal of Informetrics, 2011, Vol. 5, pp. 14-26.

[17] L.T.M. Blessing and A. Chakrabarti, DRM, a design research methodology, Springer, London, 2009.

[18] N.N., Capital Project and Infrastructure Spending Outlook to 2025, PricewaterhouseCoopers LLP \& Oxford Economics, 2015.

[19] N.N., Infrastructure Productivity: How to save \$1 trillion a year, Mckinsey Global Institute, 2013.

[20] W.H. Delone and E.R. McLean, Information systems success: The quest for the dependent variable. Information System Research, 1992, No. 3, pp. 60-95.

[21] W.H. Delone and E.R. McLean, The DeLone and McLean Model of Information Systems Success: A Ten-Year Update. Journal of Management Information Systems, 2003, Vol. 19, No. 4, pp. 9-30. 